\title{
FITOTOXICIDADE DE ESPÉCIES DE ASTERACEAE CULTIVADAS SOBRE GRAMÍNEAS INFESTANTES RESISTENTES AO GLIFOSATO
}

\author{
Angélica Alves Gomes ${ }^{1}$, Angria Ferreira Donato ${ }^{1}$, Simoni Anese ${ }^{2}$
}

\begin{abstract}
RESUMO - O objetivo deste estudo foi avaliar a atividade fitotóxica dos extratos etanólicos de folhas de Guizotia abyssinica (níger) e Carthamus tinctorius (cártamo), espécies cultivadas pertencentes à família Asteraceae, sobre gramíneas infestantes e relatadas como resistentes ao glifosato (azevém e capim-amargoso). Os extratos brutos etanólicos das plantas cultivadas foram preparados na proporção de $100 \mathrm{~g}$ de material vegetal seco para $500 \mathrm{ml}$ de etanol. Após concentração, estes foram solubilizados em solução tampão e dimetil sulfóxido (DMSO) nas concentrações de 10,0; 7,5; 5,0; 2,5 e 0 mg ml-1. Os bioensaios de germinação de sementes e crescimento do azevém e capim-amargoso foram realizados em condições controladas de laboratório. Os extratos etanólicos de níger e cártamo exerceram atividade inibitória sobre a germinação de sementes de ambas gramíneas receptoras, aumentando particularmente o tempo médio de germinação. O crescimento radicular de ambas as espécies foi sensível aos extratos etanólicos, com efeito mais pronunciado nas maiores concentrações testadas. As espécies de Asteraceae avaliadas apresentam propriedades fitotóxicas e podem ser consideradas como alternativa no controle das plantas daninhas estudadas, com base em produtos naturais.
\end{abstract}

Palavras chave: alelopatia, inibição, germinação, crescimento, controle natural

\section{PHYTOSOCIOLOGY AND SUPPRESSION OF WEEDS UNDER THE EFFECT OF SOLARIZATION AND NAPIER GRASS COVER}

\begin{abstract}
The aim of this study was to evaluate the phytotoxic activity of ethanol extracts from Guizotia abyssinica (niger) and Carthamus tinctoruis (safflower) leaves, cultivated species belonging to the family Asteraceae, on weed grasses reported as resistant to glyphosate (ryegrass and bittergrass). The crude ethanolic extracts of the cultivated plants were prepared in the ratio of $100 \mathrm{~g}$ of dry plant material to $500 \mathrm{l}$ of ethanol. After concentration, these extracts were solubilized in buffer solution and dimethyl sulfoxide (DMSO) at concentrations of 10.0; 7.5; 5.0; 2.5 and $0 \mathrm{mg} \mathrm{ml-1.} \mathrm{Seed} \mathrm{germination} \mathrm{and} \mathrm{growth} \mathrm{bioassays}$ of grasses were performed under controlled laboratory conditions. The ethanolic extracts of niger and safflower exerted inhibitory activity on the germination of seeds of both grasses, particularly increasing the average germination time. The root growth of both species was sensitive to ethanolic extracts, with a more pronounced effect in the highest concentrations tested. The evaluated Asteraceae species present phytotoxic properties and can be considered as an alternative in the control of the studied weeds, based on natural products.
\end{abstract}

Keywords: allelopathy, inhibition, germination, growth, natural control

\footnotetext{
${ }^{1}$ Discentes do curso de agronomia, Instituto Federal de Mato Grosso (IFMT), Campus Campo Novo do Parecis, MT.

${ }^{2}$ Doutora em Ecologia e Conservação de Recursos Naturais - UFSCar e Docente de EBTT, Instituto Federal de Mato Grosso (IFMT), Campus Campo Novo do Parecis, MT. E-mail: simoni.anese@cnp.ifmt.edu.br
} 


\section{INTRODUÇÃO}

As plantas daninhas são definidas como espécies que se desenvolvem onde não são desejadas, ou seja, crescem espontaneamente em solos agrícolas e em outras áreas de interesse do homem (Brighenti \& Oliveira, 2011). Como forma de controle das mesmas são utilizados os agroquímicos. Porém, seu uso em excesso tem causado o surgimento de biótipos de plantas daninhas resistentes a certos herbicidas. O conceito de resistência, referese à habilidade hereditária de uma planta sobreviver e se reproduzir, após a exposição a uma dose de herbicida normalmente letal para o biótipo selvagem da espécie (Christofoleti \& Ovejero, 2008). Dentre os herbicidas registrados e utilizados no Brasil, o principal é o glyphosate, ele atua inibindo a enzima 5enolpiruvilchiquimato-3-fosfato-sintase (EPSPS) e bloqueia a rota do ácido chiquímico (Velini et al., 2009). Para este herbicida existem relatos de 37 casos de plantas daninhas resistentes em todo o mundo, e no Brasil, são 8 casos registrados (HEAP, 2017). Dentre estas plantas, estão as gramíneas azevém (Lolium multiflorum) e capim-amargoso (Digitaria insularis) (Vargas et al., 2007; Gemelli et al., 2012; HEAP, 2017).

Nesse sentido, buscam-se soluções que possam diminuir o uso excessivo de herbicidas sintéticos que trazem implicações negativas ao meio ambiente, saúde humana e animal, além do surgimento de biótipos resistentes dentro das populações de plantas daninhas. Uma alternativa é o uso de fitotoxinas naturais que são capazes de causar alelopatia, processo que envolve metabólitos especiais (aleloquímicos) produzidos por plantas, microrganismos, vírus e fungos que influenciam o crescimento e desenvolvimento de sistemas agrícolas e biológicos (Alves et al., 2003). Estes compostos podem ser liberados por meio de diferentes mecanismos incluindo volatilização, lixiviação foliar ou exsudação radicular. Aleloquímicos têm sido relatados por apresentarem potente atividade inibitória da germinação e crescimento de plantas daninhas (Teerarak \& Charoenying, 2012; Grisi et al., 2015; Tuyen et al., 2018). A alelopatia pode desempenhar um papel importante no controle de plantas daninhas, na proteção e restabelecimento de cultivos. A manipulação adequada da alelopatia para a melhoria da produtividade das culturas e proteção do meio ambiente através do controle natural de plantas daninhas, pragas e doenças nas culturas, além da síntese de novos agroquímicos a base de produtos naturais tem recebido a atenção proeminente de cientistas envolvidos em pesquisas alelopáticas (Chon \& Nelson, 2010).

A espécie Guizotia abyssinica (Lf) Cass (Asteraceae), conhecida popularmente como níger, originária da Etiópia, é a única espécie cultivável do gênero Guizotia (Gordin et al., 2014). As folhas da espécie são ricas em flavonoides (Kuo et al., 2007), classe de metabólitos secundários relatada na literatura pelo potencial alelopático (Taiz \& Zeiger, 2010). A cultura é amplamente adaptada para todos os tipos de solo, exige chuvas moderadas e cresce em zonas temperadas e tropicais (Bottega et al., 2013) e é considerada uma espécie promissora para produção de fitomassa quando utilizada como cobertura (Carneiro et al., 2008).

A espécie Carthamus tinctorius L. (Asteraceae), conhecida popularmente como cártamo ou açafrão, é uma oleaginosa não convencional, e sua matéria-prima é destinada para a produção de óleo na alimentação humana, animal e produção biodiesel. Em países onde é cultivado em larga escala, o cártamo é utilizado em rotações com culturas de cereais, o que promove a diversificação dos sistemas de cultivo, a quebra dos ciclos de doenças e controla o surgimento de plantas espontâneas (Omidi et al., 2012). Al-Snafi (2015) cita a presença de ácidos fenólicos, alcalóides e flavonóides na espécie, classes de compostos relatadas por ocasionarem interferência alelopática.

Poucos trabalhos investigaram as propriedades fitotóxicas de G. abyssinica e C. tinctorius. Assim, o objetivo desse estudo foi avaliar a atividade fitotóxica de extratos etanólicos de folhas de níger e cártamo sobre a germinação e crescimento de plântulas de espécies infestantes resistentes ao glifosato: azevém (Lolium multiflorum) e capim-amargoso (Digitaria insularis).

\section{MATERIALE MÉTODOS}

Folhas frescas e inteiras de níger e cártamo foram coletadas nos meses de dezembro de 2016 e março de 2017, respectivamente, em canteiros na área de cultivo experimental do Instituto Federal de Mato Grosso (IFMT), Campus Campo Novo do Parecis. Posteriormente, foram secas em estufa de circulação forçada de ar, a $40^{\circ} \mathrm{C}$, e trituradas em moinho industrial, até obtenção de um pó. Os extratos etanólicos foram preparados utilizandose 100 g de material vegetal seco (pó) em $500 \mathrm{ml}$ de etanol. O material vegetal foi extraído exaustivamente no escuro, permanecendo em repouso, por $72 \mathrm{~h}$ a $4^{\circ} \mathrm{C}$. 
Em seguida, foi filtrado e concentrado em rota evaporador, sobre pressão reduzida, produzindo o extrato etanólico bruto.

Para o preparo das soluções avaliadas nos bioensaios, alíquotas do extrato bruto foram solubilizadas em solução tampão (10 mM de ácido 2-[N-morfolino] ácido etanossulfônico (MES) e $1 \mathrm{M}$ de $\mathrm{NaOH}, \mathrm{pH}=$ 6) e DMSO (dimetilsulfóxido, $5 \mu \mathrm{l} \mathrm{ml}^{-1}$ ) para a obtenção das concentrações de 10,0; 7,5; 5,0 e 2,5 mg ml-1. Além destas concentrações, em cada bioensaio foi realizado um controle com solução tampão e DMSO (5 $\left.\mu \mathrm{l} \mathrm{ml}^{-1}\right)$ (Grisi et al., 2013; Grisi et al., 2015).

Para o bioensaio de germinação, sementes das espécies-alvo foram distribuídas em placas de Petri de $90 \mathrm{~mm}$ de diâmetro, contendo duas folhas de papel filtro qualitativo $\left(80 \mathrm{~g} \mathrm{~m}^{2}\right)$, umedecidas com $5 \mathrm{ml}$ das diferentes concentrações dos extratos das espécies de Asteraceae e do controle, separadamente. O delineamento experimental foi totalmente casualizado, com 4 repetições de 20 sementes das espécies-alvo por tratamento. As placas foram seladas com Parafilm $\AA$ e o experimento instalado em câmara de germinação tipo B.O.D, em condições de fotoperíodo de $12 \mathrm{~h}$ de luz e temperatura constante de $25^{\circ} \mathrm{C}$. O registro do número de sementes germinadas foi realizado diariamente, com eliminação das sementes germinadas, sendo o critério da avaliação a protrusão de qualquer parte do embrião.

Para o bioensaio de crescimento, sementes de cada uma das espécies-alvo foram pré-germinadas, em água destilada, nas mesmas condições citadas para o bioensaio de germinação. Quatro repetições de 10 sementes prégerminadas (com radícula entre 2 e 4 mm de comprimento), foram transferidas para caixas plásticas transparentes (8 $\times 12 \times 3 \mathrm{~cm})$, contendo duas folhas de papel de filtro, umedecidas com $5 \mathrm{ml}$ de cada concentração e o controle. As caixas foram envolvidas em sacolas plásticas transparentes e mantidas em câmara B.O.D, nas mesmas condições de luz e temperaturas adotadas para o teste de germinação, em delineamento experimental totalmente casualizado. Decorridos sete dias do transplante, foram avaliados o comprimento da parte aérea e da raiz primária, com auxilio de um paquímetro digital, e a presença e registro de anomalias morfológicas.

Os dados obtidos para os parâmetros avaliados em cada bioensaio foram submetidos a análise de variância (ANOVA), seguida pelo teste de Scott Knott, a 0,05 de probabilidade, nos bioensaios de germinação e pelo teste de Dunnett, a 0,05 de probabilidade, para comparações em relação ao controle nos bioensaios de crescimento. Neste teste, os dados são apresentados como porcentagem de inibição ou estímulo do crescimento em relação ao controle. Zero representa o controle, valores positivos implicam no estímulo do parâmetro analisado, e os negativos a inibição.

\section{RESULTADOS E DISCUSSÃO}

O extrato etanólico de folhas de níger inibiu significativamente o crescimento de plântulas e algumas características de germinação de sementes avaliadas em azevém. Observou-se interferência no índice de velocidade de germinação das sementes, com valores mínimos nas maiores concentrações testadas, e no tempo médio de germinação, com incrementos significativos nas concentrações de 50 e $100 \mathrm{mg} \mathrm{ml}^{-1}$. A porcentagem de germinação das sementes de azevém não foi afetada (Tabela 1).

O crescimento inicial da parte aérea de azevém não foi influenciado pelo extrato das folhas de níger. Não houve diferença significativa das diferentes concentrações avaliadas em relação ao controle (Figura 1A). Em relação ao crescimento radicular, foi observado valores de inibição do crescimento de 50\% em relação ao controle nas concentrações mais elevadas do extrato (Figura 1B).

Para a espécie capim-amargoso, foi observado efeito inibitório do extrato etanólico de níger sobre o índice de velocidade de germinação e sobre o tempo médio de germinação, a partir da concentração 50\%. A porcentagem final de sementes germinadas não foi alterada sob efeito do extrato (Tabela 2).

Para o comprimento radicular de capim-amargoso observou-se um estímulo de crescimento na concentração de 2,5\% do extrato de níger (Figura 2B), não sendo observadas alterações para as demais concentrações sobre o crescimento da parte aérea e radicular, em relação ao controle (Figuras 2A e 2B).

De acordo com Rizvi \& Rizvi (1992), os aleloquímicos podem afetar estruturas citológicas e ultra-estruturais; hormônios, tanto alterando suas concentrações quanto o balanço entre os diferentes hormônios; membranas e sua permeabilidade; respiração; síntese de proteínas; atividade enzimática; relações hídricas e condução; material genético, induzindo alterações no DNA e RNA, 
afetando, consequentemente, a germinação e desenvolvimento vegetal. Para ambas gramíneas avaliadas no presente estudo, o extrato de níger não afetou o percentual final de germinação, mas sim interferiu na velocidade e tempo médio de germinação. O tempo médio de germinação é um fator importante para a sobrevivência de plantas daninhas, tendo em vista que plantas que germinam mais lentamente podem mostrar tamanho reduzido, menor competição por recursos e menos chances de estabelecimento no meio ambiente (Souza et al., 2010; Grisi et al., 2013).

Ainda, de acordo com Ferreira \& Aquila (2000), os aleloquímicos inicialmente agem no interior da planta para depois observarmos os sintomas, sendo que primeiramente na germinação os efeitos começam a

Tabela 1 - Efeito fitotóxico de diferentes concentrações do extrato etanólico de folhas de níger sobre as características de germinação de azevém

\begin{tabular}{cccc}
\hline Concentrações $\left(\mathrm{mg} \mathrm{ml}^{-1}\right)$ & PG $(\%)$ & IVG (sementes h $\left.{ }^{-1}\right)$ & TMG (dias) \\
\hline 0,0 (controle) & $77,50 \mathrm{a}$ & $0,25 \mathrm{a}$ & $3,89 \mathrm{a}$ \\
2,5 & $71,25 \mathrm{a}$ & $0,21 \mathrm{~b}$ & $4,64 \mathrm{a}$ \\
5,0 & $65,00 \mathrm{a}$ & $0,20 \mathrm{c}$ & $5,66 \mathrm{~b}$ \\
7,5 & $57,50 \mathrm{a}$ & $0,18 \mathrm{c}$ & $5,00 \mathrm{a}$ \\
10,0 & $45,00 \mathrm{a}$ & $0,16 \mathrm{c}$ & $6,48 \mathrm{~b}$ \\
\hline
\end{tabular}

PG (\%) - porcentagem de germinação; IVG (sementes h-1) - índice de velocidade de germinação; TMG (dias) - tempo médio de germinação. Letras iguais na mesma coluna não diferem entre si pelo teste de Scott-Knott, a 0,05.

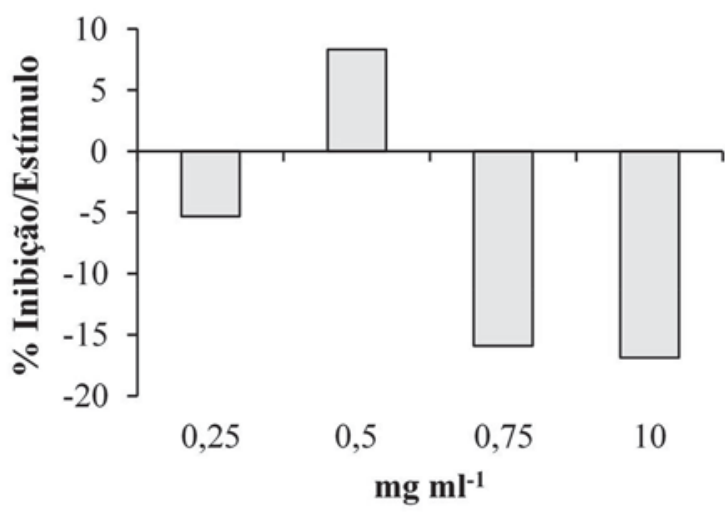

(A)

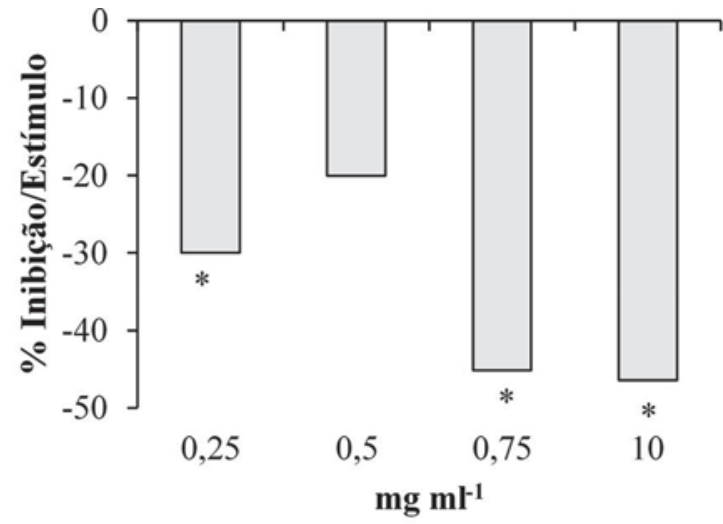

(B)

Figura 1 - Efeito das diferentes concentrações $\left(\mathrm{mg} \mathrm{ml}^{-1}\right)$ do extrato etanólico de níger sobre o crescimento da parte aérea (A) e radicular (B) de plântulas de azevém. (*) Médias diferem significativamente do controle pelo teste de Dunnet, a 0,05.

Tabela 2 - Efeito fitotóxico de diferentes concentrações do extrato etanólico de folhas de níger sobre características de germinação de capim-amargoso

\begin{tabular}{cccc}
\hline Concentrações $\left(\mathrm{mg} \mathrm{ml}^{-1}\right)$ & PG $(\%)$ & IVG (sementes $\left.\mathrm{h}^{-1}\right)$ & TMG (dias) \\
\hline 0,0 (controle) & $37,0 \mathrm{a}$ & $0,21 \mathrm{a}$ & $4,96 \mathrm{a}$ \\
2,5 & $38,50 \mathrm{a}$ & $0,18 \mathrm{a}$ & $5,36 \mathrm{a}$ \\
5,0 & $37,00 \mathrm{a}$ & $0,15 \mathrm{~b}$ & $6,68 \mathrm{a}$ \\
7,5 & $20,00 \mathrm{a}$ & $0,11 \mathrm{~b}$ & $8,95 \mathrm{~b}$ \\
10,0 & $22,00 \mathrm{a}$ & $0,11 \mathrm{~b}$ & $8,92 \mathrm{~b}$ \\
\hline
\end{tabular}

PG (\%) - porcentagem de germinação; IVG (sementes h-1) - índice de velocidade de germinação; TMG (dias) - tempo médio de germinação. Letras iguais na mesma coluna não diferem entre si pelo teste de Scott-Knott, a 0,05. 


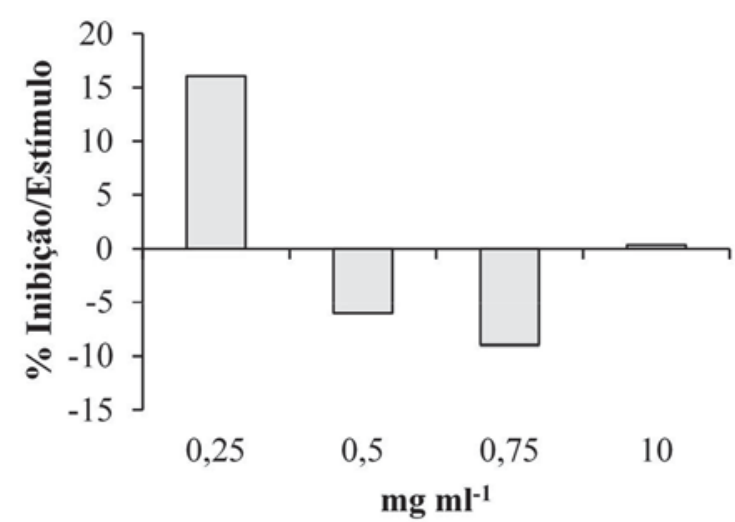

(A)

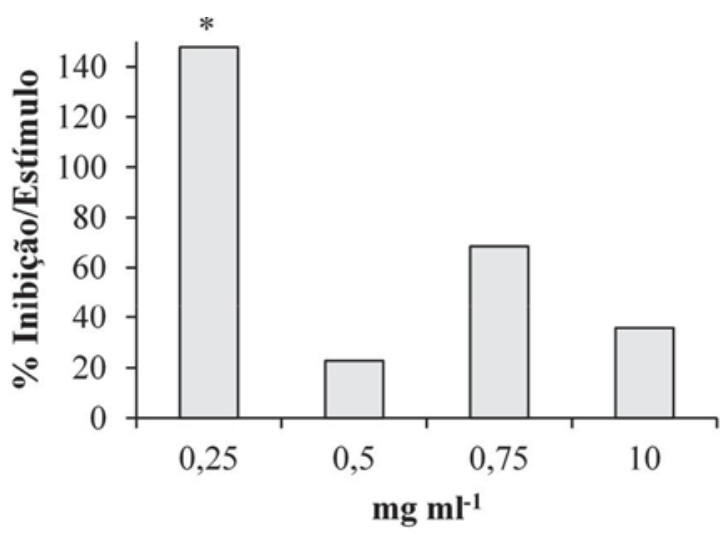

(B)

Figura 2 - Efeito das diferentes concentrações $\left(\mathrm{mg} \mathrm{ml}^{-1}\right)$ do extrato etanólico de níger sobre o crescimento da parte aérea (A) e radicular (B) de plântulas de capim-amargoso. (*) Médias diferem significativamente do controle pelo teste de Dunnet, a 0,05 de probabilidade.

nível celular. Afetando cada vaso condutor da planta, impedindo que seus fotoassimilados sejam distribuídos igualmente, causando distúrbios no desenvolvimento do vegetal.

A sensibilidade das raízes aos aleloquímicos é a característica que melhor indica a ação alelopática de extratos vegetais. Estudos anteriores também documentaram este aspecto da maior sensibilidade do crescimento sistema radicular em comparação ao da parte áerea (Tanveer et al., 2012; Grisi et al., 2015). No presente estudo, o extrato etanólico de níger não ocasionou efeito inibitório sobre o desenvolvimento da parte aérea de ambas as gramíneas. Para o crescimento radícular foi observado efeito inibitório somente para o azevém. Estes dados diferem dos encontrados por outros autores que investigaram espécies de gramíneas, a exemplo de capim-arroz (Grisi et al., 2013; Tuyen et al., 2018), braquiária e capim-colonião (Carvalho et al., 2015), em que observaram forte fitotoxidade de extratos vegetais sobre o crescimento inicial de raízes e parte aérea destas espécies. Substâncias químicas com atividade alelopática estão presentes em todos os órgãos das plantas. Entretanto, a distribuição das substâncias não é uniforme, havendo variações em função da espécie e do órgão da planta analisado.

O extrato etanólico de folhas de cártamo apresentou potencial fitotóxico, com efeito inibitório sobre a porcentagem de germinação, índice de velocidade de germinação, tempo médio de germinação e comprimento radicular do azevém, principalmente, a partir da concentração de 5,0 mg ml-1 (Tabela 3 e Figura 3). Foi observado também, efeito estimulante do crescimento da parte aérea de azevém quando em concentração de 2,5 $\mathrm{mg} \mathrm{l}^{-1}$ do extrato de cártamo (Figura 3).

No parâmetro porcentagem de germinação e comprimento da parte radicular do azévem (Figura 3B), foi observada acentuada redução em comparação ao controle. Caso o mesmo efeito fosse observado em campo, isso poderia ser prejudicial ao desenvolvimento das plântulas da espécie infestante realizando, assim, seu controle, uma vez que as raízes são responsáveis pela manutenção das funções vitais da planta, como absorção de nutrientes e água, comprometendo assim o desenvolvimento do vegetal (Kerbauy, 2008).

O aumento no tempo médio de germinação e a consequente redução da velocidade da mesma apresentam-se como fator positivo para a área cultivada, provocando atrasos na germinação das sementes, podendo, em muitos casos, levar ao não desenvolvimento natural das plantas, o que torna o controle exercido pelos aleloquímicos uma opção ecologicamente correta de controle de plantas invasoras. Alternativas como essas reduzem a necessidade de utilização de herbicidas sintéticos, diminuindo os impactos sobre o meio ambiente, problemas de resistência de plantas e efeitos na saúde humana (Inoue et al., 2010).

$\mathrm{Na}$ análise dos dados realizada para o capimamargoso, submetido aos efeitos do extrato etanólico 
Tabela 3 - Efeito fitotóxico de diferentes concentrações do extrato etanólico de folhas de cártamo sobre as características de germinação de azevém

\begin{tabular}{clcc}
\hline Concentrações $\left(\mathrm{mg} \mathrm{ml}^{-1}\right)$ & PG $(\%)$ & IVG $\left(\right.$ sementes $\left.\mathrm{h}^{-1}\right)$ & TMG (dias) \\
\hline 0,0 (controle) & $72,50 \mathrm{a}$ & $0,21 \mathrm{a}$ & $4,67 \mathrm{a}$ \\
2,5 & $64,75 \mathrm{a}$ & $0,25 \mathrm{a}$ & $4,05 \mathrm{a}$ \\
5,0 & $44,00 \mathrm{~b}$ & $0,18 \mathrm{~b}$ & $5,30 \mathrm{a}$ \\
7,5 & $53,00 \mathrm{~b}$ & $0,16 \mathrm{~b}$ & $6,23 \mathrm{~b}$ \\
10,0 & $35,00 \mathrm{~b}$ & $0,14 \mathrm{~b}$ & $6,78 \mathrm{~b}$ \\
\hline
\end{tabular}

PG (\%) - porcentagem de germinação; IVG (sementes h-1) - índice de velocidade de germinação; TMG (dias) - tempo médio de germinação. Letras iguais na mesma coluna não diferem entre si pelo teste de Scott-Knott, a 0,05.

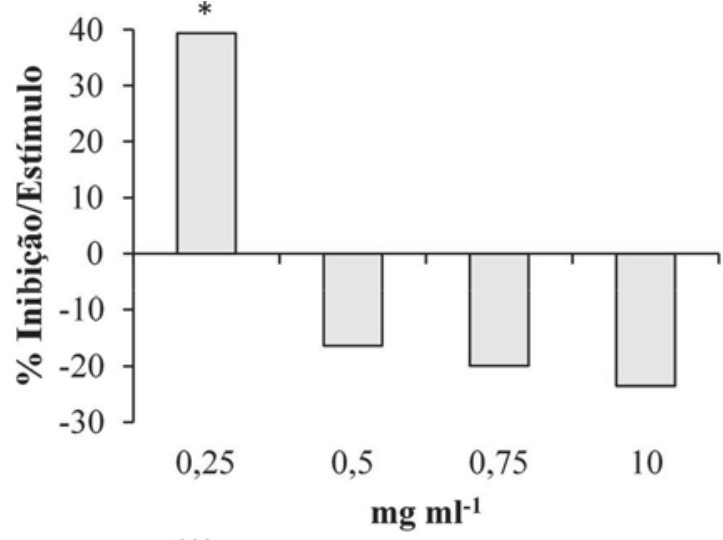

(A)

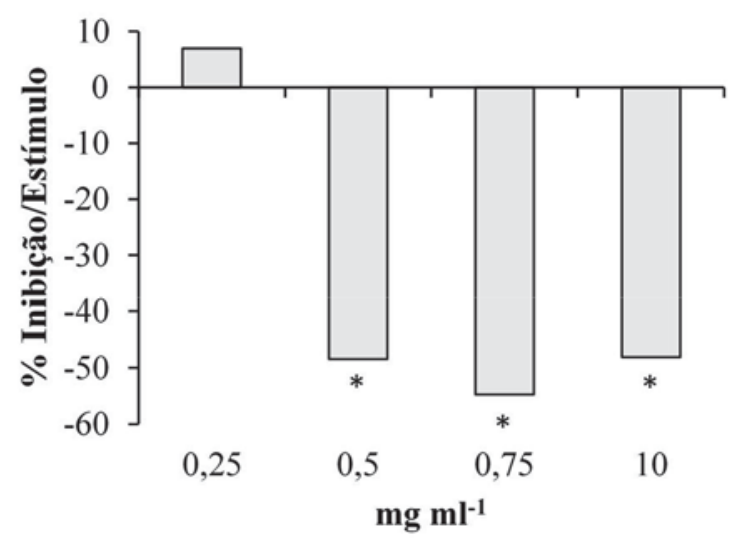

(B)

Figura 3 - Efeito das diferentes concentrações (mg ml-1) do extrato etanólico de cártamo sobre o crescimento da parte aérea (A) e radicular (B) de plântulas de azevém. (*) Médias diferem significativamente do controle, pelo teste de Dunnet, a 0,05 de probabilidade.

de cártamo, observou-se, em comparação ao controle, que todas as concentrações testadas reduziram significativamente a porcentagem de germinação e o índice de velocidade de germinação (Tabela 4), evidenciando que o cártamo é potencialmente produtor de aleloquímicos que possuem capacidade de interferência em baixas concentrações. Para o tempo médio de germinação todas as concentrações também se diferenciaram do controle, sendo possível observar que a concentração que exerceu maior efeito sobre essa variável foi a de 7,5 mg ml-1 do extrato (Tabela 4).

O comprimento da parte aérea do capim-amargoso não foi influenciado pelas concentrações testadas, fato antagônico ao observado para o crescimento da parte radicular, em que o desenvolvimento foi inibido pelas concentrações de 0,75 e $10 \mathrm{mg}$ ml-1 do extrato etanólico de cartámo (Figura 4 A e B).
Os resultados obtidos no desenvolvimento deste estudo permitem inferir que as plantas cultivadas avaliadas, ambas da família Asteraceae, apresentam potencial fitotóxico particularmente sobre o crescimento de plantas daninhas resistentes ao glifosato, investigadas no presente estudo. As Asteraceae são excepcionalmente ricas em metabólitos secundários que servem como compostos de armazenamento ou como defensores químicos. Para esta diversidade de constituintes químicos já foram comprovadas atividades farmacológicas diversas, atividade bactericida, inseticida, antioxidante, citotóxica e alelopática (Verdi et al., 2005; Ilori et al., 2007).

\section{CONCLUSÕES}

O extrato etanólico de níger apresenta fitotoxicidade sobre o azevém, evidenciada por meio do incremento 
Tabela 4 - Efeito fitotóxico de diferentes concentrações do extrato etanólico de folhas de cártamo sobre as características de germinação de capim-amargoso

\begin{tabular}{cccc}
\hline Concentrações $\left(\mathrm{mg} \mathrm{ml}^{-1}\right)$ & PG $(\%)$ & IVG (sementes $\left.\mathrm{h}^{-1}\right)$ & TMG (dias) \\
\hline 0,0 (controle) & $52,50 \mathrm{a}$ & $0,23 \mathrm{a}$ & $4,38 \mathrm{a}$ \\
2,5 & $36,00 \mathrm{~b}$ & $0,16 \mathrm{~b}$ & $6,16 \mathrm{~b}$ \\
5,0 & $30,00 \mathrm{~b}$ & $0,15 \mathrm{~b}$ & $6,79 \mathrm{~b}$ \\
7,5 & $33,00 \mathrm{~b}$ & $0,13 \mathrm{~b}$ & $7,50 \mathrm{c}$ \\
10,0 & $28,00 \mathrm{~b}$ & $0,12 \mathrm{~b}$ & $7,74 \mathrm{~d}$ \\
\hline
\end{tabular}

PG (\%) - porcentagem de germinação; IVG (sementes h-1) - índice de velocidade de germinação; TMG (dias) - tempo médio de germinação. Letras iguais na mesma coluna não diferem entre si pelo teste de Scott-Knott, a 0,05.

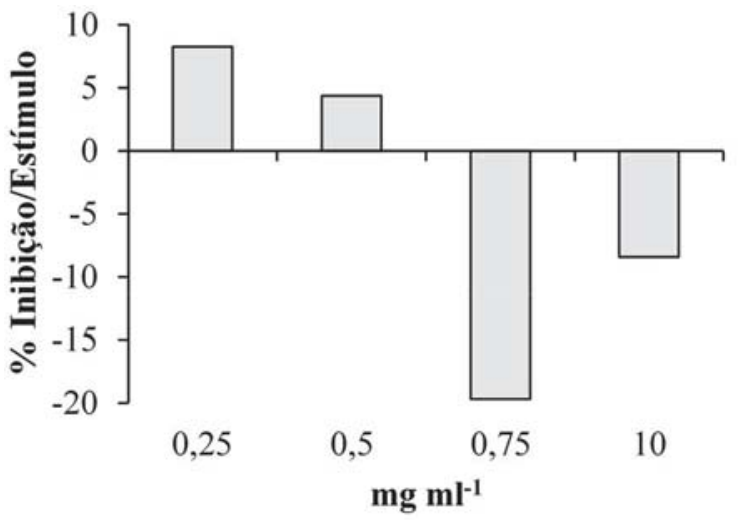

(A)

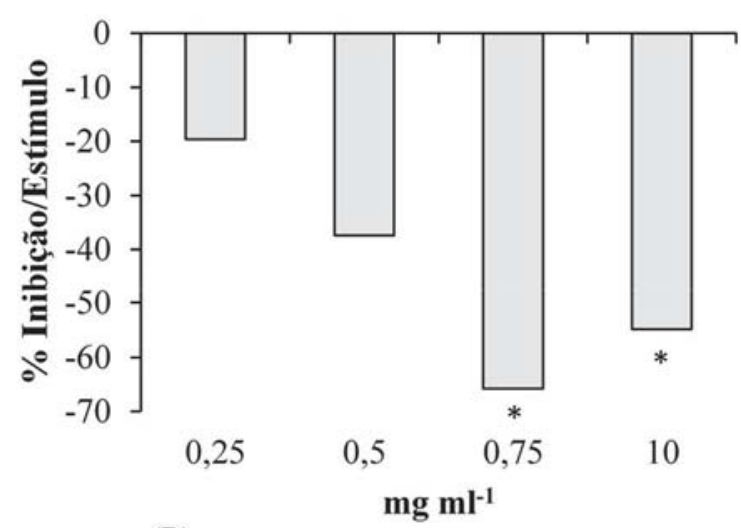

(B)

Figura 4 - Efeito das diferentes concentrações (mg ml-1) do extrato etanólico de cártamo sobre o crescimento da parte aérea (A) e radicular (B) de plântulas de capim-amargoso. $\left(^{*}\right)$ Médias diferem significativamente do controle, pelo teste de Dunnet, a 0,05 de probabilidade.

do tempo médio de germinação, redução do índice de velocidade de germinação e crescimento radicular; para o capim-amargoso são observadas interferências inibitórias nas variáveis índice de velocidade de germinação e tempo médio de germinação, não sendo observado efeito sobre o crescimento de plântulas.

O extrato etanólico de cártamo apresenta fitotoxidade em ambas gramíneas infestantes estudadas, com inibição da porcentagem de germinação, tempo médio de germinação e comprimento da parte radicular.

\section{AGRADECIMENTOS}

À Pró-Reitoria de Pesquisa e Inovação do IFMT pelo suporte financeiro; e à Fapemat pela concessão da bolsa de iniciação científica.

\section{LITERATURA CITADA}

ALVES, C.C.F.; ALVES, J.M.; SILVA, T.M.S. et al. Atividade alelopática de alcalóides glicosilados de Solanum crinitum Lam. Floresta e Ambiente, v.10, n.1, p.93-97, 2003.

AL-SNAFI, A. The chemical constituents and pharmacological importance of Carthamus tinctorius - an overview. Journal of Pharmaceutical Biology, v.5, n.3, p.143-166, 2015.

BRIGHENTI, A.M.; OLIVEIRA, M.F. Biologia de plantas daninhas. In: OLIVEIRA Jr, R.S.; CONSTANTIN, J.; INOUE, I.H. (Orgs) Biologia e manejo de plantas daninhas. Curitiba: Omnipax, 2011. p.01-36. 
BOTTEGA, M.P.; RECH, J.; SOUZA, L.C.F. et al. Desempenho agronômico do níger em função da época de semeadura para a Região Sul do Mato Grosso do Sul. Pesquisa Agropecuária Gaúcha, v.19, p.88-94, 2013.

CARNEIRO, M.A.C.; CORDEIRO, M.A.S.; ASSIS, P.C.R. et al. Produção de fitomassa de diferentes espécies de cobertura e suas alterações na atividade microbiana de solo de cerrado. Bragantia, v.67, p.455-462, 2008.

CARVALHO, F.P.; MELO, C.A.D.; MACHADO, M.S. et al. The allelopathic effect of Eucalyptus leaf extract on grass forage seed. Planta Daninha, v.33, p.193-201, 2015.

CHON, S.U.; NELSON, C.J. Allelopathy in Compositae plants. A review. Agronomy for Sustainable Development, v.30, p.349-358, 2010.

CHRISTOFFOLETI, P.J.; LÓPEZ-OVEJERO, R.F. Resistência das plantas daninhas a herbicidas: definições, bases e situação no Brasil e no mundo. In: CHRISTOFFOLETI, P.J. (Coord.) Aspectos da resistência de plantas daninhas a herbicidas. 3.ed. Piracicaba: Associação Brasileira de Ação a Resistência de Plantas aos Herbicidas HRAC-BR, 2008. p.9-34.

FERREIRA, A.; AQUILA, M.E.A. Alelopatia: uma área emergente da ecofisiologia. Revista Brasileira Fisiologia Vegetal, v.12 (Edição Especial), p.175204, 2000.

GEMELLI, A.; JUNIOR, R.S.O.; CONSTANTIN, J. et al. Aspectos da biologia de Digitaria insularis resistente ao glyphosate e implicações para o seu controle. Revista Brasileira de Herbicidas, v.11, p.231-240, 2012.

GORDIN, C.R.B.; MARQUES, R.F.; MASETTO, T.E. et al. Temperaturas e disponibilidades hídricas do substrato na germinação de sementes de niger. Bioscience Journal, v.30, p.112-118, 2014.

GRISI, P.U.; FORIM, M.R.; COSTA, E.S. et al. Phytotoxicity and identification of secondary metabolites of Ssapindus saponaria L. leaf extract. Journal of Plant Growth Regulation, v.39, p.339349, 2015.
GRISI, P.U.; GUALTIERI, S.C.J.; ANESE, S. et al. Efeito do extrato etanólico de Serjania lethalis no controle de plantas daninhas. Planta Daninha, v.31, p.239-248, 2013.

HEAP, I.A. The international survey of herbicide resistant weeds. Disponível em: <http:// www.weedscience.org>. Acesso em: 27 abr. 2017.

ILORI, O.; OTUSANYA, O.; ADELUSIS, A. Phytotoxic effects of Tithonia diversifolia on germination and growth of Oryza sativa. Research Journal of Botany, v.2, p.23-32, 2007.

INOUE, M.H.; SANTANA, D.C.; SOUZA FILHO, A.P.S. et al. Potencial alelopático de Annona crassiflora: Efeitos sobre plantas daninhas. Planta Daninha, v.28, p.489-498, 2010.

KERBAUY, G.B. Fisiologia vegetal. Rio de Janeiro: Guanabara Koogan S.A., 2008. 431p.

KUO, WEN-LUNG; CHEN, CHIEN-CHIH.; CHANG, PO-HAO.et al. Flavonoids from Guizotia abyyssinica. Chinese Medical Journal, v.18, p.121-128, 2007.

OMIDI, A. H.; KHAZAEI, H.; MONNEVEUX, P.; STODDARD, F. Effect of cultivar and water regime on yield and yied componentes in sanfflower (Cartthamus tinctorius L.). Turkish Journal of Field Crops, v.17, p.10-15, 2012.

RIZVI, S.J.H.; RIZVI, V. Exploration of allelochemicals in improving crop productivity. In: Allelopathy: basic and applied aspects. London: Chapman \& Hall, 1992. p.443-472.

SOUZA, F.M.; GANDOLFI, S.; PEREZ, S.C.J.G.A. et al. Allelopathic potential of bark and leaves of Esenbeckia leiocarpa Engl. (Rutaceae). Acta Botânica Brasílica, v.24, p.169-174, 2010.

SOUZA FILHO, A.P.S. Potencialidades alelopáticas envolvendo gramíneas e leguminosas forrageiras e plantas invasoras de pastagens. 1995. 137 f. Tese (Doutorado em Zootecnia) Universidade Estadual Paulista, Jaboticabal, 1995.

SOUZA FILHO, A.P.S.; RODRIGUES, L.R.A.; RODRIGUES, T.J.D. Efeitos do potencial alelopático de três leguminosas forrageiras sobre três invasoras de pastagens. Pesquisa Agropecuária Brasileira, v.32, p.165-170, 1997. 
TAIZ, L.; ZEIGER, E. Fisiologia vegetal. 3. ed. Porto Alegre: Artmed, 2010. 719p.

TANVEER, A.; JABBAR, M.K.; KAHLIQ, A. et al. Allelopathic effects of aqueous and organic fractions of Euphorbia dracunculoides L. on germination and seedling growth of chickpea and wheat. Chilean Journal of Agricultural Research, v.72, p.495-501, 2012.

TEERARAK, M.; CHAROENYING, P. Physiological and cellular mechanisms of natural herbicide resource from Aglaia odorata Lour. on bioassay plants. Acta Physiologiae Plantarum, v.34, p.12771285, 2012.

TUYEN, P.T.; XUAN, T.D.; TU ANH, T.T. et al. Weed Suppressing Potential and Isolation of Potent Plant Growth Inhibitors from Castanea crenata Sieb. et Zucc. Molecules, v.23, p.345, 2018.

Recebido para publicação em 3/6/2018 e aprovado em 12/3/2019.
VARGAS, L.; MORAES, R.M.A.; BERTO, C.M. Herança da resistência de azevém (Lolium multiflorum) ao glyphosate. Planta Daninha, v.25, p.567-571, 2007.

VARGAS, L.; ROMAN, E.S. Identificação e manejo de plantas daninhas resistentes a herbicidas. EMBRAPA Trigo, setembro, 2006.

VELINI, E.D. et al. Modo de ação do glyphosate. In: VELINI, E.D. et al. Glyphosate. Botucatu: FEPAF, 2009. 496p.

VERDI, L.G.; BRIGHENTE, M.I.; PIZZOLATTI, M.G. Gênero Baccharis (Asteraceae): Aspectos químicos, econômicos e biológicos. Química Nova, v.28, p.85-94, 2005. 